\title{
Dualidade e ambivalência da identidade docente de bacharéis que atuam em cursos de licenciaturas
}

\author{
Diego Carlos Pereira \\ Universidade Estadual Paulista "Júlio de Mesquita Filho" \\ Váldina Gonçalves da Costa \\ Universidade Federal do Triângulo Mineiro
}

\section{Resumo}

Esse artigo resulta de uma pesquisa de mestrado focada no estudo da identidade docente de professores formadores, considerando a constituição da identidade como processo relacional individual e coletivo que permeia as trajetórias formativas e educacionais. $\bigcirc$ objetivo deste artigo é problematizar e argumentar a respeito das características duais e ambivalentes da constituição da identidade docente de professores bacharéis que atuam em cursos de Licenciatura, considerando os aspectos formais e biográficos das trajetórias dos sujeitos. O estudo pautou-se em perspectiva qualitativa a partir da metodologia da História oral e da análise das narrativas de professores formadores bacharéis. Defendemos que a dualidade do processo se caracteriza entre a formação bacharelesca e a atribuição ao cargo de docente conferida pela legislação educacional e pelo contexto acadêmico; enquanto a ambivalência se expressa por meio do conflito entre ser bacharel/pesquisador e ser professor no ensino superior, diante das demandas distintas que esses dois papeis profissionais podem provocar.

Palavras-chave:Identidade docente. Professores bacharéis. Formação de professores. História oral.

\section{Duality and ambivalence of teaching identity of bachelor's professors who works on teacher training undergraduate}

\section{Abstract}

This article results from a master's research focused on the study of the teacher identity of trainers' professors, considering the identity constitution as an individual and collective relational process that permeates the formative and educational trajectories. This paper aims to discuss and present arguments about the dual and ambivalent features of the teaching identity constitution process from bachelor's lecturers, who works in teacher's training undergraduate courses, considering the formal and biographical aspects of the subjects' trajectories. This study was based on a qualitative perspective from de oral History and the narrative analysis from bachelor's teacher trainers. We argue that the duality of the identity process is characterized by a relationship between the bachelor's formation and the attribution to the teaching position conferred by educational legislation and the academic context. On the other hand, the ambivalence is expressed through the conflict between being a bachelor/researcher and being a teacher in higher education, especially in teacher training, faced with the distinct demands that these two professional roles can cause.

Keywords: Teacher's identity. Bachelor's professors. Teacher's training undergraduate. Oral history. 


\section{Dualidad y ambivalencia de la identidad docente de graduados que actúan en cursos de formación de profesores}

\section{Resumen}

Este artículo resulta de una investigación de maestría enfocada en el estudio de la identidad docente de profesores formadores, considerando la constitución de la identidad como proceso relacional individual y colectivo que impregna las trayectorias formativas y educativas. El objetivo del artículo es problematizar y argumentar acerca de las características duales y ambivalentes de la constitución de la identidad docente de sujetos graduados (especialistas en sus áreas específicas), pero que actúan como profesores en cursos de formación docente, considerando los aspectos formales y biográficos de las trayectorias de ellos. El estudio se basó en perspectiva cualitativa por medio de la metodología de Historia oral y del análisis narrativa de los profesores graduados. Defendemos que la dualidad del proceso se caracteriza entre la formación específica/técnica y la atribución al cargo de docente conferida por la legislación educativa y por el contexto académico; mientras que la ambivalencia se expresa por medio del conflicto entre ser graduado/técnico/investigador y ser profesor en la enseñanza superior, ante las demandas distintas que estos dos papeles profesionales pueden provocar.

Palabras clave: Identidad docente. Profesores graduados. Formación de profesores. Historia oral.

\section{Introdução}

A temática relacionada à identidade docente tem se constituído como uma das principais vertentes de interesse das pesquisas em educação, tendo em vista a sua importância no âmbito da consideração dos sujeitos em seus aspectos sociais, temporais e espaciais. Assim, os processos educacionais têm sido ponderados a partir das relações humanas e, consequentemente, das identidades constituídas pelos sujeitos ao longo desses processos e sua interferência nos modos e singularidades da educação.

Desta maneira, este trabalho se relaciona a uma pesquisa de mestrado, com bolsa financiada pela Coordenação de Aperfeiçoamento de Pessoal de Nível Superior (CAPES), realizada em uma universidade pública de Uberaba, Minas Gerais; investigação esta que se dedicou ao tema da identidade docente e das trajetórias formativas de professores de cursos de Licenciatura que possuem formação de Bacharelado em áreas específicas, ao mesmo tempo em que formam professores.

A Lei de Diretrizes e Bases da Educação Nacional (BRASIL, 1996), em seu artigo $n^{\circ} 66$, esclarece que a preparação (não formação) legal para 
o exercício do magistério superior fica sob responsabilidade prioritária (não obrigatória) dos programas de mestrado e doutorado. Diante dessa realidade, nos questionamos a respeito da formação didático-pedagógica de professores que em seu processo formativo fizeram cursos específicos de bacharelado e cursaram seus mestrados e doutorados sem uma preocupação específica com a docência e/ou ensino.

Tendo em vista esse pressuposto legal que é pouco específico quanto à formação formal do professor do ensino superior, há ainda o questionamento social e simbólico sobre as representações e sentimentos dos professores bacharéis em relação à docência, à sua constituição profissional e ao seu pertencimento à profissão. Afinal, esses professores não tinham a intenção inicial de serem docentes ao realizar um curso de natureza bacharelesca, mas em algum momento de sua trajetória as circunstâncias e o processo formativo os fizeram exercer o magistério e, portanto, puderam reconstruir ou não suas intencionalidades e pertenças em relação à profissão docente.

Este artigo se dedica a esse aspecto da constituição da identidade docente dos professores bacharéis, pois pressupomos que o Bacharelado se caracteriza como um aspecto formativo em âmbito formal dos sujeitos, no 176 entanto, consideramos que esse elemento não é determinante quanto à identidade e os vínculos que os sujeitos podem constituir em relação à docência, seja em sua trajetória pessoal ou em sua prática profissional.

Nosso texto, então, consiste em um trabalho argumentativo sobre os processos de constituição da identidade docente de professores bacharéis, presumindo suas características processuais no âmbito social permeadas pelo que chamamos de ambivalência (do conflito entre os sentidos) e dualidade (das duas naturezas formais entre formação e atuação) enquanto possíveis representações teóricas sobre o tema. Defendemos, assim, um teor biográfico e social da constituição da identidade docente.

Com isso, nosso objetivo neste texto é problematizar e argumentar a respeito das características duais e ambivalentes da constituição da identidade docente de professores bacharéis que atuam em cursos de Licenciatura, considerando os aspectos formais e biográficos das trajetórias dos sujeitos.

A História oral se constituiu enquanto percurso metodológico que permeou a nossa pesquisa e que compreende a nossa preocupação com os significados, sentidos e experiências que constituem os sujeitos/professores. 
Conforme Meihy (2005) e Minayo (2008) apontam, a História oral potencializa os estudos referentes à identidade, pois se relaciona ao modo como os sujeitos compreendem o seu passado, criam vínculos com suas experiências pessoais e relações sociais dando-thes significado, e, a partir disso, (re) interpretam constantemente suas práticas sociais no momento presente.

Desse modo, as narrativas produzidas pelas falas dos professores são nosso material empírico que permitem uma série de interpretações sobre a identidade docente dos professores bacharéis pesquisados. Depreendemos a análise, conforme apontado por Bolívar (2002), de um modo interpretativo sobre as narrativas, considerando sua historicidade e singularidade, sem buscar determiná-las em categorias fixas, mas com o pesquisador estabelecendo novas leituras, novas narrativas, novos significados sobre temas explorados a partir das experiências dos sujeitos.

Ressaltamos que discorrer acerca dessas relações estabelecidas entre a identidade docente e a formação de professores pressupõe um exercício constante de diálogo, discussões e construção de conhecimentos no âmbito da pesquisa acadêmica. Não tentamos esgotar a temática ou estabelecer conclusões finalísticas ou definitivas para a discussão, mas sim, buscamos contribuir para a sua problematização em âmbito científico a partir de nossa experiência de pesquisa e, obviamente, com a colaboração dos protagonistas de nosso estudo, os professores bacharéis formadores de professores pesquisados.

Além disso, este artigo está organizado em duas partes: na primeira, buscaremos realizar aproximações e distanciamentos teórico-metodológicos sobre o conceito de identidade a partir das teorias de Claude Dubar (2005), bem como, relacionar os aspectos teóricos das dimensões específicas da identidade profissional e da identidade docente; na segunda parte, aprofundaremos em nossa experiência de pesquisa, cedendo espaço às trajetórias formativas de nossos protagonistas, os professores bacharéis, potencializando as problemáticas que nos levam a interpretar as suas identidades docentes como sendo caracterizadas pela ambivalência e pela dualidade

\section{A constituição da identidade: sujeitos, socialização e experiência}

Consideramos a identidade como um processo social e, como tal, emerge como um aspecto central em nosso trabalho, visto que nos interessam 
Dualidade e ambivalência da identidade docente de bacharéis que atuam em cursos de licenciaturas

os traços desse processo construídos pelo sujeito e discutíveis a partir das narrativas dos professores bacharéis. Diante disso, presumimos que:

[...] a identidade nada mais é que o resultado a um só tempo estável e provisório, individual e coletivo, subjetivo e objetivo, biográfico e estrutural, dos diversos processos de socialização que, conjuntamente, constroem os indivíduos e definem as instituições (DUBAR, 2005, p. 136).

Dando continuidade às explanações do autor, consideramos a identidade como um processo de construção subjetiva do sujeito historicamente situado, e por isto, não é um dado imutável. Para Pimenta (2009), a identidade é legitimada e também transformada em determinado contexto e momento histórico, respondendo às necessidades que estão postas pelas sociedades.

Para a autora, a identidade do professor está relacionada à significação social da profissão e à revisão das tradições. Isso implica no confronto entre suas práticas com as teorias que se distanciam da realidade escolar, bem como com as práticas consagradas culturalmente e que permanecem significativas no cotidiano escolar.

$178 \quad$ Ainda segundo a autora, as práticas também se constroem pelo significado que cada professor, enquanto ator e autor, confere à atividade docente nas experiências de seu cotidiano e a partir de seus valores, de seu modo de situar-se no mundo, de sua história de vida, de suas representações sociais, de seus saberes, de suas angústias e anseios, do sentido que tem em sua vida o ser professor.

Assim, retomando Dubar (2005), a identidade social é marcada por uma relação intrínseca entre os aspectos subjetivos do sujeito e a relação com o outro; sendo que a identidade humana é construída desde a infância e reconstruída no decorrer da vida, bem como jamais é um processo solitário, pois está relacionado com suas próprias definições, com os juízos dos outros e com as estruturas sociais e culturais com as quais o sujeito se relaciona.

Portanto, Dubar (2005) explica que a construção das identidades sociais está relacionada com o processo de socialização que envolve uma dupla dimensão, individual e social, no âmbito relações entre os sujeitos e as instituições. $\bigcirc$ autor defende que os sujeitos constroem e reconstroem suas identidades primárias na infância, de maneira contextualizada à realidade histórica, cultural, social, geracional e familiar. 
No entanto, segundo o autor, esse processo relacional não é simples e nem determinante. Isso significa que a identidade não é condicionada, mas sim construída nas trajetórias dos sujeitos mediante suas relações e seus sentidos em articulação com as relações e os sentidos dos outros e das estruturas sociais. Desta forma, as crises ou rupturas, oriundas do contexto relacional ao longo da trajetória do sujeito, podem transformar e reconstruir as identidades radicalmente ou, por outro lado, as identidades construídas podem ser resistentes a essas rupturas, mantendo-se as estruturas construídas desde a infância do sujeito.

As resistências identitárias, que não significam que são processos imutáveis, relacionam-se, segundo Dubar (2005), à construção do habitus como produto do processo de socialização. Segundo o autor, o habitus pode resistir às rupturas identitárias do sujeito, pois reproduzem as estruturas construídas e enraizadas culturalmente em uma sociedade.

Nessa perspectiva, habitus é considerado como "[...] sistemas de disposições duráveis e transponíveis, estruturas estruturadas predispostas a funcionar como estruturas estruturantes, isto é, enquanto princípios geradores e organizadores de práticas e de representações" (BOURDIEU apud DUBAR, 2005, p. 66).

Esse conceito de habitus relaciona-se às formas e aos sistemas sociais que são duradouras e legitimadas historicamente e que se relacionam com os sujeitos desde a infância, construindo suas trajetórias e articulando-se a elas. Estas estruturas, no processo de socialização e construção da identidade, tendem a ser reproduzidas e a resistirem às crises identitárias por um sistema de poder cultural (DUBAR, 2005).

No entanto, Dubar (2005) realiza uma crítica à teoria do habitus de Bourdieu afirmando que existem elementos de incerteza quanto à reprodução estrutural do habitus, visto que os diferentes sujeitos reproduzem ou rompem com os mesmos habitus de maneiras singulares e diversificadas, mesmo sendo uma cultura dominante em um grupo.

Assim, conjecturamos que exista uma intensa relação dos cotidianos vividos pelo professor com a construção de suas identidades - mesmo diante de uma formação bacharelesca - na qual ambos se inter-relacionam considerando os aspectos de vida e profissão do professor, não dando como certas ou 
finalísticas as reproduções dos habitus, sejam eles oriundos das experiências pessoais ou dos processos formativos.

Desse modo, segundo Pimenta (2009), as identidades oscilam nas inter-relações da construção cultural e social (da vida), tratadas anteriormente, bem como da construção profissional do sujeito, tornando-se pertinente, também, realizar algumas apreciações a respeito da profissão docente e alguns de seus aspectos que influenciam no processo de constituição das identidades.

Consideramos que a infância se torna um dos aspectos a se observar no âmbito das trajetórias dos professores bacharéis, pois nas narrativas que os sujeitos relatam sobre a sua própria infância podem estar expressos como foram e se houveram processos de ruptura e construção de sentidos em relação à docência, bem como problematizá-los no âmbito da constituição da identidade docente por meio dos processos de socialização vividos por eles.

Nesse sentido, consideramos que:

A socialização é, enfim, um processo de identificação, de construção de ldentidade, ou seja, de pertencimento e de relação. Socializar-se é assumir seu pertencimento a grupos (de pertencimento ou de referência), ou seja, assumir pessoalmente suas atitudes, a ponto de elas guiarem amplamente sua conduta sem que a própria pessoa se dê conta disso (DUBAR, 2005, p. 24).

Para o autor, este processo não permite dizer que os sujeitos tenham também uma identidade única devido à multiplicidade de grupos de pertencimento ou de referência e também por estarem "[...] entre o desejo de ser como os outros, aceito pelos grupos a que pertence ou quer pertencer, e o aprendizado da diferença, até mesmo da oposição com relação a esses grupos" (DUBAR, 2005, p. 24). Com isso, os atos de pertencimento, sejam para o âmbito do conhecimento para o bacharelado, seja em sua adesão como docente, são cerne de nosso artigo e nossas interpretações.

Segundo Dubar (2005), a socialização é constituída enquanto processo biográfico e por isso não é determinante, visto que incorpora disposições psicológicas, sociais da família e da classe de origem, mas também o conjunto de sistemas estruturantes relacionadas aos demais sujeitos e as estruturas sociais. Para o autor, este processo implica em uma relação da história vivida, do passado, com as práticas e relações sociais atuais, mas esta articulação entre passado e presente é construída e transformada ao longo do tempo. 
processo de socialização realiza-se, então, na construção do que o autor chama de interlocução entre a identidade para si e a identidade para o outro.

A identidade para si é constituída no processo biográfico relacionado aos atos de pertencimento expressos pelos sentidos e significados do sujeito; é expressa pela concepção do "quem você diz que é". Ela é construída e reconstruída pelas experiências vividas do ponto de vista subjetivo do sujeito, dimensionadas pela ruptura ou reprodução dos modelos vividos (identidade herdada) e das expectativas futuras (identidade visada) (DUBAR, 2005).

Tendo a experiência como cerne das narrativas dos professores bacharéis, concordamos com Larrosa (2002, p. 21) que "[...] a experiência é o que nos passa, o que nos acontece, o que nos toca. Não o que se passa, não o que acontece, ou o que toca. A cada dia se passam muitas coisas, porém, ao mesmo tempo, quase nada nos acontece".

Para o autor, o conceito de experiência ultrapassa os limites factuais, técnicos ou concretos; deixa de ser exclusivamente empírico ou experimental, pois se estabelece de acordo com os significados (sentidos) que nós atribuímos subjetivamente; é o que nos "toca" de acordo com nossas vivências, histórias e sensações.

Neste estudo, corroborando com os pressupostos de Larrosa (2002), concebemos a experiência não apenas como um conjunto de ações ou momentos dos sujeitos pesquisados, mas, sobretudo, como uma reflexão dos sujeitos sobre si mesmos, como narradores de sua própria história e identidade, repleta de significados.

Larrosa (2002, p. 4) distancia ainda o conceito de experiência de sua noção empírica voltada ao experimento ou de práticas realizadas pelos sujeitos. Para o autor, a experiência está relacionada à vida dos sujeitos, pois se constrói "[...] não a partir da ação, mas da paixão, a partir de uma reflexão do sujeito sobre si mesmo do ponto de vista da paixão".

Assim, as experiências dos professores bacharéis representam produção de sentidos e sensibilidades ao longo de sua trajetória narrada e, para nós, estes elementos constituem-se como expressão singular do processo de constituição da identidade destes colaboradores da maneira contextualizada e vivida por eles.

Já a identidade para o outro é construída no processo relacional e mobilizada pelos atos de atribuição expressos pelos sentidos e significados dos 
outros sujeitos e instituições em relação a você; é expressa pela concepção do "quem dizem que você é". Ela é construída e reconstruída pela maneira em que o sujeito incorpora essa atribuição feita pelo outro que pode gerar processos de pertencimento ou não pertencimento a tais atribuições (DUBAR, 2005). Nesse sentido, um bacharel pode construir uma identidade docente quando The é atribuída essa função pelo Estado, pela Universidade ou mesmo pelos alunos e, ao mesmo tempo, o sujeito pode socializar esse pertencimento por meio de suas experiências.

Assim, Cunha (2010) afirma que é importante abarcar as relações entre a instituição e a sociedade em uma conexão espaço-tempo. Para a autora, o professor é determinante na relação com a instituição por ser um sujeito capaz de promover transformações em sua estrutura e, ao mesmo tempo, também é determinado por um contexto e um conjunto de situações e circunstâncias que são embrenhadas no cotidiano de sua atuação profissional.

Com isso, a partir das socializações, nosso estudo considerou que é nas relações com as instituições e os sujeitos que o professor vai depreender os seus valores e os seus conhecimentos no contexto de uma determinada circunstância institucional, na qual se estabelece a vivência de sua prática

182 pedagógica e social. Compreendendo as instituições de ensino como instituições sociais e, portanto, espaços de produção e reprodução das relações sociais, o professor como sujeito historicamente situado assume um papel primordial na construção do contexto social (CUNHA, 2010).

Esta interlocução processual entre a identidade de si e a identidade para o outro constitui o âmago das relações de constituição da identidade dos sujeitos, de maneira processual e biográfica, relacional e objetiva. Diante do processo relacional constituído pela socialização, Dubar (2005) demonstra que não há distinção entre identidade social e identidade profissional, conforme veremos a seguir.

\section{A dimensão das identidades profissionais}

Para Dubar (2005), não existe uma distinção prática entre o processo de constituição de uma identidade social e de uma identidade profissional, pois o aspecto profissional relaciona-se diretamente com os processos biográficos, que são individuais, e com processos relacionais, que são sociais. Segundo o 
autor, na construção da identidade profissional como especificidade de análise, permanecem a relações intrínsecas entre a identidade de si e a identidade para o outro.

A identidade profissional é uma dimensão da identidade social do sujeito. No entanto, de acordo com Dubar (2005), este dimensionamento profissional da identidade pode conferir-the uma intensa ruptura devido às delicadas formas de divisão do mercado de trabalho e suas próprias estruturas. Deste ponto, mesmo sendo uma dimensão, o aspecto profissional pode reconstruir a identidade social de um sujeito, ou parte dela, perante o processo de socialização.

Dessa forma, o autor explica que as identidades profissionais se constituem simultaneamente entre as formas identitárias de viver o trabalho e seus processos relacionais, os sentidos do trabalho e de conceber a vida profissional no tempo biográfico, em âmbito subjetivo. Estas formas dependem do contexto histórico e variam de acordo com o espaço.

Uma interface do processo de constituição de identidade profissional enaltecida por Dubar (2005) é a relação de pertencimento a uma coletividade estruturada socialmente por uma linguagem técnica e por valores em comum, constituída pelo processo de formação profissional em articulação com sua identidade social. Nesse sentido, a identidade dos professores bacharéis entra em cheque: afinal, ser bacharel especialista em uma área específica de conhecimento ou ser professor? Tendo em vista que esses dois grupos profissionais (bacharel/professor) possuem suas especificidades, nosso artigo vislumbra avançar neste aspecto da discussão sobre identidade de professores.

$\bigcirc$ pertencimento a um corpo coletivo enquanto elemento para a profissionalidade refere-se, segundo Roldão (2005), ao compartilhamento, organização e defesa da função de uma profissão em seu grupo, ou seja, implica reconhecer em um grupo o poder e a especificidade profissional. Assim, a pertença é legitimada em uma comunidade de profissionais que defendem o prestígio, a credibilidade e a exclusividade de seu saber coletivo; no caso da docência, a autora defende o "ensinar" enquanto a sua função/ ação profissional.

Os professores no ensino superior, muitas vezes, trazem consigo a trajetória acadêmica (do bacharelado e da pós-graduação) de sua área de ałuação e pesquisa e nem sempre se questionam sobre o que significa ser 
professor. Ao mesmo tempo, as instituições os recebem pressupondo que são professores como se estivessem prontos para a atuação profissional, não se preocupando em formá-los continuamente como professores; "Assim sua passagem para a docência ocorre 'naturalmente'; dormem profissionais e pesquisadores e acordam professores!" (PIMENTA; ANASTASIOU, 2005, p. 104). Então nos questionamos: como é esse processo de mudança/ruptura nas trajetórias dos professores bacharéis?

A construção da pertença profissional efetiva-se enquanto processo formativo na área de conhecimento e na adesão aos conhecimentos e função profissionais; portanto, os cursos de formação são espaços pelos quais os professores se profissionalizam. Para Pimenta e Anastasiou (2005), no caso dos professores do ensino superior, não há um espaço claro e legitimado de profissionalização pela docência, nem mesmo os sujeitos escolhem ser professores universitários.

Para as autoras, no Brasil este processo é presumido por um senso comum de que qualquer pesquisador, legitimado pela titulação e por dominar sua área de conhecimento, já seja um professor universitário. Ora, então como se constitui o processo de identidade destes professores? Conjecturamos que o processo de pertencimento se constitui nas referências e nas experiências que o sujeito vive em sua trajetória que, apesar de não serem formais, podem ser suficientes para eles se afirmarem como professores.

A estrutura da universidade ainda estimula pouco, segundo Roldão (2005), a construção e a articulação de um grupo coletivo que fortaleça a função profissional da docência nas universidades. Para a autora, esta relação de pertença ainda é mais intensa para a identificação dos profissionais como pesquisadores ou mesmo como profissionais em seus cursos específicos, como engenheiros, médicos, historiadores, geógrafos, matemáticos e outros, mesmo atuando como "professores do magistério superior", segundo a própria denominação prevista na legislação.

Diante disso, nos questionamos até que ponto os professores bacharéis realizam esta relação de pertencimento à profissão docente em seu exercício profissional e se de fato se posicionam profissionalmente em relação às especificidades de sua função. Presumimos que esta inquietação nos leva às discussões do processo de constituição de identidade, pois entendemos que no estudo deste processo é que as relações de pertencimento emergem nas 
narrativas dos sujeitos da pesquisa, bem como as demais relações de sentido e significado da identidade docente.

A discussão da identidade no âmbito de Dubar (2005), mesmo que o autor não especifique sua teoria no âmbito da identidade docente, nos permite um posicionamento que incita questionarmos esse processo de socialização com os professores bacharéis, pois, considerando que qualquer profissional antes de tudo é um sujeito, percebemos que a constituição profissional dos mesmos também perpassa o âmbito pessoal e, sobretudo, a identidade social que os mesmos atribuem a si, seus sentidos e sensibilidades produzidas por suas experiências.

\section{Das narrativas a uma interpretação da identidade docente dos professores bacharéis caracterizada pela ambivalência e dualidade}

É importante ressaltarmos que não buscamos delimitar ou categorizar o conceito de identidade, ou mesmo generalizar concepções a respeito da identidade docente de professores bacharéis. $\bigcirc$ próprio conceito de identidade, como explicitamos anteriormente, é considerado a partir de uma série de aspectos coletivos, sociais, individuais e culturais dos sujeitos em seus processos biográficos, não permitindo generalizações.

A nossa análise trata-se de uma interpretação possivel a partir das narrativas de cinco professores bacharéis que atuam em cursos de Licenciatura diversos em uma universidade pública de Uberaba, Minas Gerais. Este texto, então, constitui-se de uma leitura, dentre tantas que podem ser feitas a partir das narrativas desses sujeitos. É a representação de nossa própria identidade de professores/pesquisadores (re) constituída na relação com as narrativas dos sujeitos pesquisados. Essa interpretação é uma expressão da nossa identidade enquanto texto!

Adentraremos em aspectos das trajetórias dos professores formadores Miguel (Biologia), Alice (Matemática), Arthur (Matemática), Sophia (Letras) e Davi (Química) - nomes fictícios -, para discutir suas experiências formativas para a docência a partir de suas narrativas, potencializando aspectos íntimos e pessoais dos sujeitos, ou seja, dos significados construídos pelas pessoas ao longo da vida para sua relação com a docência, constituindo identidade (s). 
Salientamos que, por conta do formato de redação para artigo, as narrativas não estão completas neste texto, então, exporemos alguns trechos das narrativas que possibilitam nossa leitura.

Ao defendermos a interpretação de que os professores bacharéis pesquisados constituem suas identidades processualmente no âmbito social, cultural, histórico e espacial, consideramos, como veremos a seguir, que seus atos de pertencimento à docência se estabelecem por uma relação mútua entre a dualidade formal de sua profissão (são bacharéis/pesquisadores de formação, mas são legitimados, por meio legal ou pelos grupos, como professores formadores de professores e, ao mesmo tempo, a ambivalência de sentidos para a profissão e seus conflitos ("ser bacharel x ser professor" ou "ser pesquisador $x$ ser professor").

A seguir, vamos especificar alguns aspectos que as narrativas nos permitem interpretar a respeito da dualidade e da ambivalência que, para nós, caracterizam a identidade docente dos professores bacharéis pesquisados. Porém, frisamos aqui que de maneira nenhuma pode-se perder de vista que o que caracterizamos como "dualidade" e "ambivalência" possuem uma relação mútua de dependência e transformação contínua no processo biográfico de

186 constituição da identidade dos sujeitos pesquisados, não sendo lineares.

\section{A relação mútua entre dualidade e a ambivalência na constituição da identidade docente de professores bacharéis}

Pensar a identidade docente de professores bacharéis esbarra em uma problemática central acerca dos processos formativos formais que thes conferem, total ou parcialmente, atos de pertencimento à profissão docente. É no entremeio dessa problemática que se destaca um processo dual na constituição da identidade docente desses sujeitos, afinal, eles possuem processos formais de formação que não tinham o objetivo de torná-los docentes, mas ao mesmo tempo, o contexto acadêmico, os outros sujeitos, a universidade e a própria legislação thes conferem atos de pertencimento à profissão docente.

Dessa forma, o aspecto da dualidade na constituição da identidade docente de professores bacharéis está intrinsicamente relacionado aos processos formativos dos sujeitos (graduação e pós-graduação) ao passo que atuam profissionalmente como professores de cursos de licenciatura, formando outros 
Diego Carlos Pereira | Váldina Gonçalves da Costa

professores, cujas atribuições de conhecimentos e demandas profissionais não são oriundos, originalmente, das suas formações.

Inferimos, tendo como fundamento Dubar (2005), que as experiências formativas se constituem por processos de socialização que não são isolados apenas ao ato de pertencimento dos cursos. Obviamente é uma construção histórico-biográfica do sujeito e uma socialização sucessiva e articulada à infância, aos caminhos transitórios, aos contextos sociais e às características pessoais dos sujeitos. Significa que a formação é um elemento articulado à trajetória do sujeito e não é estática e definitiva, pois depende da reconstrução de processos de socialização anteriores e ainda pode ser reconstruída a posteriori por novos processos de socialização. Ou seja, consideramos que nem um curso de bacharelado ou de licenciatura sejam capazes de definirem, por si só, os sujeitos que se identificam como professores e os que não.

Mesmo observando nas narrativas dos professores bacharéis as limitações formativas do ponto de vista da didática nos cursos de formação inicial e de pós-graduação, as experiências formativas foram expostas de maneira singular em cada trajetória, provocando referências e reflexões diferentes para cada vivência nos seus respectivos processos de socialização.

Os atos de pertencimento dos sujeitos à profissão são reconstruídos em sua formação inicial de acordo com o contexto social e institucional, bem como sofrem rupturas ao se depararem com a possibilidade de formação acadêmica na pós-graduação. $\bigcirc$ que nos intriga neste processo são as dualidades das experiências formativas, pois a decisão, em lugar da atuação profissional como bacharel, de seguir a formação acadêmica passa a ser um ato de pertencimento, consciente ou não, de assumir a docência no ensino superior. Observamos que passa a ser um aspecto articulado e inerente às trajetórias. Como podemos observar nas narrativas a seguir:

Quando eu comecei o curso de Química eu almejava trabalhar na indústria. O que eu tinha em mente era a possibilidade que eu via na época de ir pra indústria, não via outra ałuação pra quem formasse em Química. Mas com o passar do tempo, me inserindo no meio acadêmico, fui me deparando com novas informações e novas expectativas e isso foi contribuindo muito pra tirar o meu foco da indústria. Me deu um 'start' lá pela iniciação científica que me fez olhar pra pós-graduação de outra forma. [...] pelos professores que eu tive e que me influenciaram também. Eu tinha lá os professores da USP, de cursos que são consolidados e então todo o trabalho 
Dualidade e ambivalência da identidade docente de bacharéis que atuam em cursos de licenciaturas

de pesquisa era consolidado. E aí eu decidi continuar os estudos na pós-graduação (PROFESSOR DAVID, 2015).

$[\ldots]$

Se me perguntasse se eu sabia o que era um bacharelado, não sabia. Eu só sabia que eu não queria ser professora. [...] Aí, quando eu prestei o vestibular eu optei por fazer o bacharelado porque eu não queria ser professora, foi a única escolha que eu fiz consciente que era a de não ser professora. E a escolha pela Matemática foi por afinidade mesmo (...) Eu sabia que eu queria na área de matemática, porque no primeiro dia de aula eu já queria ser uma pesquisadora em matemática, na primeira aula eu fui já convencida a isso pelos meus professores (PROFESSORA ALICE, 20151 .

Nas narrativas desses dois professores bacharéis, assim como no caso dos demais sujeitos da pesquisa, existem em suas trajetórias opções inicialmente claras quanto ao curso de bacharelado por um objetivo inicial específico, alheio à expectativa pela docência enquanto profissão. É, como nos casos explanados, até um ato de pertencimento consciente dos sujeitos em seguir suas carreiras como profissionais e pesquisadores específicos de suas 188 áreas de conhecimento.

questionamento que fazemos é: como, diante dessas expectativas profissionais e de uma formação específica na área escolhida, esses sujeitos redefinem seus sentidos profissionais para a docência? As narrativas dos professores David e Alice já apontam para os processos de socialização, permeados pelo contexto da instituição em que se formaram e pelos professores que tiveram, como elementos que redefiniram suas trajetórias profissionais. A narrativa do professor Miguel é ainda mais contundente ao abordar esse ponto:

Apesar de desde criança querer ser pesquisador em paleontologia, eu não sabia como as coisas funcionavam aqui no Brasil e na graduação percebi que para ser pesquisador no Brasil eu teria que ser professor. Daí, eu comecei a colocar isso na cabeça e com o tempo eu passei a ver que ser professor não era uma coisa ruim como eu pensava. Eu realmente pensava quando criança: 'ah vou não vou ser professor, vou ser pesquisador', como se fosse uma coisa com menos mérito. E percebi que isso era bobagem, falta de instrução, falta de orientação. Depois, quando a gente começa a ver o professor universitário que não é só aula dentro de sala [...] isso começou a me preparar pra ser professor. Na UFU eu tive certeza de que eu 
queria ser professor porque eu via os professores nos gabinetes o dia inteiro, pois o curso era integral e eu morava praticamente dentro do campus... eu vivia lá! (PROFESSOR MIGUEL, 2015).

Nesse sentido, observamos que nas narrativas dos professores bacharéis o peso do sentido do "ser pesquisador" está diretamente atrelado à constituição da identidade docente e de seu aspecto de dualidade. $\bigcirc$ contexto histórico e espacial da academia/universidade permeado pelo poder da pesquisa acadêmica constitui, a partir dos pressupostos de Dubar (2005), uma série de disposições sociais e culturais que os sujeitos buscam reproduzir na coletividade, um sistema social fruto das sucessivas socializações de experiência na formação desses sujeitos; o que, segundo o autor, constituiria um habitus.

Ou seja, o processo de socialização permeado por uma cultura acadêmica de produção cientifica, de projetos e de grupos redefinem as expectativas e os sentidos dos sujeitos, então, em formação inicial em seus cursos de bacharelado, direcionando-os para o processo de formação em pós-graduação.

Como a própria narrativa do professor Miguel expõe e que mencionamos anteriormente frente aos preceitos legais (BRASIL, 1996), é na pós-graduação que a formação do professor para o ensino superior acontece de maneira prioritária. Diante dos pressupostos teóricos apresentados por Dubar (2005) e Pimenta e Anastasiou (2005), podemos admitir que o status da pós-graduação e o Estado, diante dos dispositivos legais, já conferem aos bacharéis o pertencimento à profissão docente.

Tendo em vista que a identidade é conferida também pela relação e as atribuições feitas pelo outro e pelo contexto social, os sujeitos pesquisados têm na pós-graduação a atribuição de seus próprios sentidos, diante das socializações, a seu pertencimento enquanto professor do ensino superior. Consideramos, assim, que os professores bacharéis se sentem professores a partir do momento que a pós-graduação e o contexto de pesquisa thes conferem a atribuição e o reconhecimento enquanto docentes do ensino superior.

É nesse sentido que defendemos a constituição de suas identidades permeadas pela dualidade do processo. Pois ao mesmo tempo em que suas formações não se constituem como processos formais de formação de 
professores, os contextos sociais e culturais da universidade lhes conferem atributos de docentes do ensino superior, constituindo novos sentidos da identidade para si.

Não estamos defendendo ou sugerindo que apenas o fato dos bacharéis cursarem a pós-graduação já thes é suficiente para serem professores, ao contrário. Estamos defendendo que o atual contexto acadêmico e o modo como são formados os professores do ensino superior no Brasil confere atributos para uma identidade do sujeito à profissão docente. No entanto, pressupomos assim como Pimenta e Anastasiou (2005) e Roldão (2005), que para ser professor, além de uma identidade conferida pelas atribuições de sentido e pelas experiências, os sujeitos precisam ser formados tendo em consideração uma série de conhecimentos e demandas que são específicas à profissão docente.

Nesse sentido, as narrativas dos professores bacharéis pesquisados alertaram para o fato de que, com os seus respectivos cursos de pós-graduação, os sujeitos se sentiam preparados para assumir as atividades de pesquisa na universidade, mas não se sentiam formados para as atividades de ensino, conforme podemos observar no seguinte relato:

Eu vejo hoje que os programas ou pelo menos o programa do qual eu participei, traz de certa forma uma deficiência porque a parte didática, da prática docente exatamente não é muito tratada no programa de pós-graduação. Nós éramos focados no aprimoramento de conteúdo e desenvolvimento de coleta de dados, tratamentos e análises dos resultados, ele enfoca muito esse campo. Claro que tinha lá umas disciplinas voltadas pra seminários, mas não era o foco. Por mais que eu estivesse ali pra fazer as atividades de pesquisa, não tinha muito o olhar de como ser um docente, um professor (PROFESSOR DAVID, 2015).

Esse aspecto da formação na pós-graduação é recorrente não só na narrativa do professor David, mas também em todos os demais professores pesquisados. Pimenta e Anastasiou (2005) já apontavam para essa problemática nos cursos de pós-graduação em todas as áreas de conhecimento, pois há uma concentração nos esforços de se formar pesquisadores e pouco ou nunca se menciona a formação e o trabalho desse pesquisador enquanto professor do ensino superior. Este aspecto narrado pelo sujeito implica na ideia socialmente e historicamente construída na universidade e legitimada pela legislação 
de que a formação do professor para o ensino superior é focada na formação do pesquisador.

Para os professores bacharéis Arthur, Alice, David, Miguel e Sophia, é na pós-graduação que as experiências formativas reconstroem os atos de pertencimento profissionais para se pensar a academia como forma de acesso à profissão docente no ensino superior. Este ato de pertencimento é conscientemente definido para os sujeitos diante das sucessivas socializações e experiências por meio da cultura científica permeada no meio acadêmico.

Desse modo, as experiências formativas, seja na graduação, no bacharelado ou na pós-graduação, articulam-se biograficamente aos sucessivos processos de socialização pessoal e institucional dos sujeitos. Tanto o bacharelado quanto a pós-graduação não são processos isolados e constroem atos de pertencimento profissionais dinâmicos e situados perante o contexto das instituições e da vida dos colaboradores. Constituem experiências repletas de emoções, traumas, decisões, incertezas, superações e realizações que são inerentes à constituição da identidade destes professores.

Diante da dualidade apresentada enquanto aspecto da constituição da identidade dos professores bacharéis pesquisados, pois não possuem uma formação específica que thes atribuam a profissão docente, mas são permeados por um contexto de pesquisa, de grupo social e de legislação que os legitimam e os fazem sentir professores do ensino superior, nos questionamos: se não é no processo de formação que os professores bacharéis constituem suas experiências para atender às demandas e conhecimentos necessários para ser docente, onde eles as constitui?

É no âmbito desse questionamento que argumentamos que a dualidade que caracteriza a constituição da identidade docente de professores bacharéis é mutuamente permeada por um processo também ambivalente. Ao defender uma identidade caracterizada pela ambivalência, buscamos na semântica do termo ambivalência (FERREIRA, 2010) o pressuposto da coexistência de dois valores de sentidos ou aspectos diferentes, opostos ou não, que se complementam e, ao mesmo tempo, podem conflitar. Significa pensar que os sentidos construídos pelos sujeitos em suas narrativas não os determinam e nem os excluem de processos de constituição de uma identidade entre o ser bacharel e ser professor formador, uma identidade mediadora entre os sentidos opostos. 
Enquanto a dualidade que caracteriza a constituição da identidade docente dos professores bacharéis se relaciona com os atributos conferidos pelos outros (grupo social, universidade e legislação) - ou identidade para o outro -, a ambivalência se constitui como uma característica identitária dos próprios sentidos dos sujeitos em relação mútua com a dualidade conferida pelos outros; é um aspecto construído nos entremeios do processo biográfico dos professores pesquisados.

A caracterização do processo de constituição da identidade dos professores bacharéis pela ambivalência se expressa por meio das sucessivas socializações em meio à atuação no magistério superior. É nos processos de socialização com os alunos, com os demais professores e com o contexto institucional que os sentidos ambivalentes entre o ser professor e ser bacharel/ pesquisador são expressados nas narrativas. Salientamos que não consideramos aqui que ser bacharel é o mesmo que ser pesquisador, nem que apenas os bacharéis são pesquisadores. Ao usarmos os temos dessa maneira, queremos empreender que os sentidos atribuídos pelos professores à sua atividade profissional como bacharéis se relacionam diretamente ao desenvolvimento de pesquisa em sua atividade profissional.

As experiências com as práticas docentes e com o trabalho no ensino superior emergem significativamente nas narrativas dos professores bacharéis pesquisados, cada um com suas singularidades. Os sujeitos relatam como as experiências docentes marcaram suas trajetórias provocando reflexões, rupturas, redefinições e promovendo novos olhares para a docência e para o ser professor. As narrativas dos professores bacharéis expõem diversos aspectos singulares no sentido de que suas reflexões a respeito da atuação docente e do processo de socialização em sala de aula marcam as suas constituições profissionais, conflitam suas experiências formativas e reelaboram os conhecimentos mobilizados em sua atuação profissional. Observamos as narrativas a seguir:

[...] se você comete um erro numa conta no quadro [...] nossa!!!! Você está ferrado mesmo! Porque depois o aluno acha que por conta de um erro seu você não tem domínio e aí você tem que reagir com jogo de cintura pra que sua relação com o aluno seja mais tranquila. Com o tempo eu fui trocando de estratégia, pra contornar essa dificuldade minha de lidar com as contas em sala de aula, eu passei a desafiar eles antes a fazer, então eles tentam fazer antes e conforme eles acertam ov erram as contas a gente vai chegando 
aos resultados e aí eu faço junto com eles (PROFESSOR ARTHUR, 2015).

[...]

Depois do doutorado eu atuei sete anos na Universidade Federal do Vale do Jequitinhonha e Mucuruí, junto ao curso de farmácia bioquímica de lá. Esse contato foi desafiador porque eu não tinha tido nenhuma experiência no ensino superior até então [...] mas o que mais me chamou atenção foi o desafio, porque eu sabia que no ensino superior demandaria de outras estratégias, deveria se buscar um maior aprofundamento no transpassar o conteúdo (PROFESSOR DAVID, 2015).

[...]

Nas minhas primeiras aulas num curso de Licenciatura eu encarei uma turma que me dizia "ah, mas aonde vou usar isso professora?" [...] Então foram questionamentos que eu não tinha como responder. Onde eles iam usar isso? Como iam aplicar na sala de aula? Porque que é importante isso? e aí eu preciso dizer que eu nunca havia me perguntado, porque eu achava que enquanto bacharel, que eu precisava aprender o necessário pra ser um bom pesquisador e essas questões de ensino nunca passaram pela minha formação, até então eu nunca tinha precisado disso. Eu nunca tinha pensado na relação que a derivada integral tem com o que o aluno vai trabalhar na educação básica. Então foram questões que nunca tinham passado pelo meu horizonte, nunca tinha pensado em questionar, por exemplo, o porquê que eu tinha que aprender estruturas algébricas, apenas me disseram que eu tinha que aprender na disciplina, estava na minha grade e eu fiz! Acho que o grande benefício de ter ido dar aula é que eu talvez passasse pelo mestrado e pelo doutorado sem nunca me fazer esses questionamentos (PROFESSORA ALICE, 2015).

[...]

que eu sempre faço e que também que eu fui aprendendo como professora e com os alunos é que eu normalizo as notas. $\bigcirc$ que vai acontecendo é que você vai conhecer tanto de um assunto que você sempre vai olhar pra prova de um aluno e achar que aquilo não é suficiente. Então o que eu faço é dar dez pro aluno que melhor respondeu a minha prova e então eu venho normalizando as notas. Eu acho mais justo e acho que coloca uma responsabilidade em mim que é a de que se tem algo que ninguém respondeu é porque eu não fui capaz de ensinar, acho que essa é uma visão crítica que a gente tem que ter, ou seja, não existe nada que não seja passível de ser compreendido (PROFESSORA SOPHIA, 2015). 
Podemos interpretar com esses trechos das narrativas e com outros relatos de experiência narrados durante a pesquisa que os sujeitos se sentem professores no processo de socialização com os alunos, pois são os alunos que thes atribuem o papel simbólico e a função de professor em sala de aula, com relações pessoais e de poder diferenciadas que o fazem reconstruir seus próprios atos de pertencimento e reelaborar seus conhecimentos mobilizados na prática docente no ensino superior.

As narrativas dos professores expõem, de uma maneira geral, que existe um atributo que thes confere sentido ao realizar a atividade docente, o qual eles pensam que seja fundamental para serem professores: o conteúdo. Para nós, esse aspecto em comum nas narrativas dos professores bacharéis se relaciona às atribuições que foram construídas biograficamente nos processos de socialização que os sujeitos viveram. A ideia de que um bom professor se relaciona ao domínio do conteúdo é um senso comum sobre a profissão docente e parece estar presente como uma concepção enraizada na formação dos professores bacharéis pesquisados. Conjecturamos que isto possa estar ligado à matriz de preocupação científica e técnica de suas trajetórias formativas.

Concordamos com Roldão (2005) que é importante que um professor tenha domínio dos conteúdos que ele ministra, no entanto, para ser professor, não é somente o conteúdo que é suficiente para a realização do ato pedagógico. $\bigcirc$ conhecimento do aspecto social, do psicológico, do ensino do conteúdo, do conhecimento didático, do conhecimento do currículo e dos objetivos educativos constituem um enredo que a realidade da docência no ensino superior exige que o professor mobilize em sua prática.

É nesse sentido que o conflito ambivalente do processo de constituição da identidade dos professores bacharéis é mais explícito, pois eles são formados para o domínio do conteúdo de suas áreas específicas, no entanto, o processo de socialização com a instituição e com os alunos provoca as sensibilidades desses sujeitos para uma mobilização de conhecimentos específicos à atividade docente e a reflexão sobre esses conhecimentos em suas práticas. $\bigcirc$ poder simbólico da formação bacharelesca pelo conteúdo se conflagra com as demandas e necessidades que entremeiam o trabalho docente. Esta mobilização e reflexão sobre as práticas docentes são, às vezes conscientes e às vezes não conscientes, mas thes conferem atributos para a sua identidade enquanto docentes. 
Os sentidos produzidos pelos professores bacharéis em suas narrativas não os determinam e nem os excluem de processos de construção de uma identidade entre o ser bacharel e ser professor formador. Inferimos que é a oposição e a contradição nos processos de socialização que os constituem como sujeitos e dimensionam seus sentidos para uma identidade profissional. São atos de pertencimento que não abandonam as marcas do bacharelado e da pós-graduação sem formação pedagógica e nem de sua trajetória pessoal, mas reconstroem novos sentidos para a docência como sua profissão nos sucessivos processos de socialização vividos, seja com outros sujeitos ou com o contexto e o espaço universitário.

Os sujeitos se constituem ao longo de sua trajetória e não deixam de ser bacharéis e nem deixam de ser professores formadores. São legitimados oficialmente pelos cargos que ocupam e títulos que possuem, sobretudo, não deixam de produzir e reproduzir sentidos para seus atos de pertencimento, sejam como bacharéis/pesquisadores ou como professores formadores de professores.

Não é a natureza do cargo e a formação que determinam ser ou não ser professor formador, esses são elementos do processo. Sobretudo, são as produções de sentidos por meio de atos de pertencimento construídos nos processos de socialização que marcam a sua identidade profissional pela docência e ao mesmo tempo pelo profissional bacharel, de maneira consciente ou não consciente das especificidades profissionais que diferenciam as duas modalidades de atuação.

Essa consideração de identidade como processo biográfico caracterizado pela ambivalência e dualidade vai ao encontro das inferências de Dubar (2005) e Roldão (2005). Mas consideramos, também, que nosso trabalho redimensiona a caracterização feita por estes autores ao denotar especificamente a constituição profissional dos professores bacharéis que vivem as ambivalências de sentidos entre a formação profissional de bacharel e pesquisador, ao qual foi formado, e as dualidades para a docência com a atuação no magistério superior, na pesquisa e na formação de professores.

No entanto, mesmo com as produções de sentidos ambivalentes que constituem profissionalmente os professores bacharéis desse estudo, pensamos que é preciso estabelecer alguns pressupostos comuns que as experiências narradas pelos colaboradores permitem realizar enquanto ressalvas à essa 
produção de sentidos. Isto é, considerar que os professores bacharéis produzem atos de pertencimento à docência, mas que esse processo também se revela com alguns limites.

$\bigcirc$ primeiro, é de considerar que no processo de formação continuada, seja como uma política institucional ou como processo de adesão pessoal à profissão, os professores bacharéis têm a oportunidade de reelaborar seus conhecimentos segundo os fundamentos teóricos, científicos, didáticos e sociais específicos da profissão docente, os quais não tiveram acesso em sua formação. Ou seja, não é a graduação e a titulação propriamente ditas que conferem a profissionalidade docente, conforme Roldão (2005), e nem mesmo só a produção de sentidos para a docência na prática. $\bigcirc$ processo de constituição profissional perpassa a produção de sentidos para a adesão à docência, mas também perpassa assumir os preceitos formais da função docente, sejam eles por meio da formação inicial, da pós-graduação e/ou da formação continuada.

segundo limite é de que a prática docente foi narrada como mobilizadora de conhecimentos para a formação docente, como ato de pertencimento profissional e como exercício da profissionalidade pelos professores

196 bacharéis. No entanto, a prática narrada não implica necessariamente na prática efetiva realizada pelos professores para a mobilização de conhecimentos para a formação de professores. É importante que os atos de pertencimento profissional docente sejam direcionados na formação dos professores formadores para a consciência na prática de que estão formando professores para o ensino básico e que a mobilização de conhecimentos perpassa, sobretudo, o conteúdo e que a partir dele se constroem os conhecimentos específicos para a ałuação docente.

O terceiro e último limite é que a relação com os alunos narrada pelos professores bacharéis reflete um contexto geracional que conflita com a prática docente dos colaboradores, pois segundo os professores, os alunos chegam nas licenciaturas reproduzindo um sistema que vem do ensino médio e, assim, chegam despreparados, com dificuldades de aprendizagem que os professores do ensino superior não conseguem e não são preparados para lidar, o que reforça o processo contínuo de formação e reflexão como cerne para a atuação profissional docente e a constituição de suas identidades. 
Diego Carlos Pereira | Váldina Gonçalves da Costa

\section{Considerações finais}

A partir dos referenciais de Dubar (2005) e de Roldão (2005), em articulação com as experiências narradas pelos colaboradores da pesquisa, nossas interpretações sugerem pensarmos que os professores bacharéis são sujeitos historicamente situados e constroem, assim como qualquer sujeito, seus atos de pertencimento nos processos de socialização que vivem e não apenas em sua formação, atribuindo sentidos às marcas e sentimentos que suas lembranças e sua atuação profissional provocam.

Admitir a sua identidade caracterizada pela ambivalência é admitir que eles são bacharéis pela formação e pelos sentidos que atribuem ao seu processo de trajetória profissional e, sobretudo, também são conscientemente professores formadores, pois atribuem sentidos aos seus atos profissionais e são legitimados pelos cargos e titulações que possuem. Esta ałuação profissional consciente ao ser professor formador de professores provoca reflexões e angústias aos professores bacharéis nos processos de socialização em sala de aula e no desenvolvimento de sua profissionalidade no âmbito institucional.

Frente aos sentidos construídos nas narrativas dos professores bacharéis, há um processo de constituição de uma dualidade em suas identidades profissionais, que corrobora com os pressupostos de Dubar (2005), entre a identidade constituída por essa ambivalência de sentidos (identidade para si) e a identidade docente conferida institucionalmente ou formalmente lidentidade para o outro). Ou seja, os professores bacharéis atuam profissionalmente com a dualidade entre a formação que possuem e o seu reconhecimento como professores pelo contexto acadêmico.

Contudo, o processo de constituição da identidade dos professores bacharéis pesquisados perpassa essa ambivalência e essa dualidade, provocando conflitos, resistências e/ ou rupturas nos processos biográficos singulares dos sujeitos. Esta implicação confere alguns processos específicos aos professores bacharéis e pressupomos que as mesmas podem ser aprofundadas cientificamente e problematizadas em âmbito científico, formativo, político e institucional.

Por fim, almejamos elucidar alguns aspectos do processo de constituição da identidade docente de professores bacharéis que atuam em cursos de licenciatura na cidade de Uberaba, Minas Gerais. O que buscamos com esse 
artigo é expor a nossa leitura diante das narrativas dos sujeitos e suas experiências, contribuindo para o debate acadêmico sobre identidade docente sem considerar que nossas proposições são finalísticas ou determinantes. Na verdade, são marcas de processos sociais dos sujeitos que contribuíram e de nós mesmos enquanto professores/pesquisadores.

\section{Referências}

BONDÍA, Jorge LARROSA. Notas sobre a experiência e o saber da experiência. Revista Brasileira de Educação, Rio de Janeiro, n. 19, p. 20-28, 2002.

BOTIA, Antonio Bolivar. "De nobis ipsis silemus?": Epistemología de la investigación biográfico-narrativa en educación. Revista Electronica de Investigación Educativa, Mexico, v. 4, n. 1, p. 1-26, 2002.

BRASIL. Lei n 9.394, de 20 de dezembro de 1996. Estabelece as diretrizes e bases da educação nacional (LDB). Diário Oficial [da] União, Poder Executivo, Brasília, DF, 23 de dezembro de 1996. Seção 1, p. 27833.

198 CUNHA, Maria Isabel da. O bom professor e sua prática. 22. ed. Campinas: Papirus, 2010.

DUBAR, Claude. A socialização: construção das identidades sociais e profissionais. Tradução Andréa Stahel da Silva. São Paulo: Martins Fontes, 2005.

FERREIRA, Aurélio Buarque de Holanda. Dicionário da língua portuguesa. 5. ed. Curitiba: Positivo, 2010.

MEIHY, José Carlos Sebe Bom. Manual de história oral. 5. ed. São Paulo: Edições Loyola, 2005.

MINAYO, Maria Cecília de Souza. 0 desafio do conhecimento: pesquisa qualitativa em saúde. 11 . ed. São Paulo: Hucitec, 2008.

PIMENTA, Selma Garrido. Formação de professores: identidade e saberes da docência: In: PIMENTA, Selma Garrido (ORG). Saberes pedagógicos e atividade docente. 4. ed. São Paulo: Cortez, 2009.

PIMENTA, Selma Garrido; ANASTASIOU, Léa das Graças Camargo. Docência no ensino superior. 2. ed. São Paulo: Cortez, 2005. 
PROFESSORA ALICE. Narrativa. Uberaba (Minas Gerais), 16 jun. 2015.

PROFESSOR ARTHUR. Narrativa. Uberaba (Minas Gerais), 25 jun. 2015.

PROFESSOR DAVID. Narrativa. Uberaba (Minas Gerais), 17 jun. 2015.

PROFESSOR MIGUEL. Narrativa. Uberaba (Minas Gerais), 28 jun. 2015.

PROFESSORA SOPHIA. Narrativa. Uberaba (Minas Gerais), 23 jun. 2015.

ROLDÃO, Maria do Céu Neves. Profissionalidade docente em análise: especificidades do ensino superior e não superior. Nuances: estudos sobre educação. Presidente Prudente/São Paulo: v. 12, n. 13, p.105-126, jan./dez. 2005.

Prof. Me. Diego Carlos Pereira

Doutorando em Geografia Universidade Estadual Paulista Júlio de Mesquita Filho | UNESP | Rio Claro Bolsista Fundação de Amparo à Pesquisa do Estado de São Paulo | FAPESP Grupo de Estudos e Pesquisa em Educação e Cultura (GEPEDUC/UFTM) E-mail | diego-carlinho@hotmail.com

Profa. Dr ${ }^{a}$. Váldina Gonçalves da Costa

Universidade Federal do Triângulo Mineiro | Uberaba Departamento de Educação em Ciências, Matemática e Tecnologias Programa de Pós-Graduação em Educação | UFTM Grupo de Estudos e Pesquisa em Educação e Cultura (GEPEDUC/UFTM) E-mail | valdina.costa@gmail.com

Recebido 21 set. 2017 Aceito 11 dez. 2017 